\title{
An update on the diagnosis and treatment of Parkinson disease
}

\author{
Philippe Rizek MD, Niraj Kumar MD DM, Mandar S. Jog MD
}

CMAJ Podcasts: author interview at https://soundcloud.com/cmajpodcasts/151179-rev

$\mathrm{P}$ arkinson disease is the second most common neurodegenerative disorder after Alzheimer disease. ${ }^{1}$ Parkinson disease typically develops between the ages of 55 and 65 years and occurs in $1 \%-2 \%$ of people over the age of 60 years, rising to $3.5 \%$ at age $85-89$ years. $^{2-4}$ About $0.3 \%$ of the general population is affected, and the prevalence is higher among men than women, with a ratio of 1.5 to $1.0 .^{5}$ Parkinson disease may be more common among white people than those of Asian or African descent; however, the data are conflicting. ${ }^{4,6}$ In 2011, the estimated number of people living with Parkinson disease in Canada had reached $85200 .^{7}$ By 2031, the projected number of people with this disease will double. ${ }^{1,7}$

Management remains complicated over the course of the disease and should be individualized based on the patient's quality of life at each stage of disease. There have been many advancements in the management of Parkinson disease and ongoing research. Many options are now available. This review presents current treatment strategies and recommendations in managing motor and nonmotor symptoms in the various stages of Parkinson disease. Methods for developing this review are outlined in Box 1.

\section{Box 1: Methods}

We used Canadian and American national guidelines to inform this review, in addition to published systematic reviews that were known to us. We identified additional articles through MEDLINE literature searches using the search terms "Parkinson disease" and "diagnosis," "treatment," "pathology," "epidemiology" or "prognosis" from 1980 to present. In addition, we reviewed conference abstracts and reference lists from seminal articles, and clinical trials currently underway (clinicaltrials.gov). Where possible, we selected the most recent articles and the articles with the most robust level of evidence (such as randomized controlled trials and meta-analyses). We reviewed more than 300 citations, of which 179 are included in this review (including those within the appendices).

\section{What is the pathophysiology of the disease?}

Parkinson disease is a neurodegenerative syndrome involving multiple motor and nonmotor neural circuits. ${ }^{8,9}$ It is characterized by two major pathologic processes: (a) premature selective loss of dopamine neurons; (b) the accumulation of Lewy bodies, composed of $\alpha$-synuclein, which become misfolded and accumulate in multiple systems of patients with Parkinson disease. It is unclear which process occurs first. Based on pathologic studies, ${ }^{10}$ there is a stepwise degeneration of neurons over many years, with each affected site corresponding to specific symptomatology in Parkinson disease (Table 1). When motor symptoms become evident, there is $30-70 \%$ cell loss evident in the substantia nigra on pathologic examination. ${ }^{11}$ The mainstay of therapy aims to replace dopamine with dopaminergic medications and modulate the dysfunctional circuit. Cognitive dysfunction, mood disorders and impulse control disorders are related to deficits of dopamine outside the basal ganglia or in serotonergic and noradrenergic systems. ${ }^{12,13}$ Autonomic dysfunction has

\author{
Competing interests: \\ Mandar Jog reports \\ honoraria from Merz \\ Pharmaceuticals, Allergan \\ and AbbVie; and grants \\ from the Canadian Institutes \\ of Health Research, \\ Academic Medical \\ Organization of \\ Southwestern Ontario, \\ Lawson Health Research \\ Institute, AGE-WELL \\ Networks of Centres of \\ Excellence, Merz \\ Pharmaceuticals and Boston \\ Scientific. He occasionally \\ serves on advisory boards \\ of Allergan, Boston \\ Scientific, AbbVie and \\ Merz Pharmaceuticals. No \\ other competing interests \\ were declared.
}

This article has been peer reviewed.

Correspondence to:

Mandar Jog,

mandar.jog@lhsc.on.ca

CMAJ 2016. DOI:10.1503

/cmaj.151179

\section{KEY POINTS}

- Parkinson disease is the second most common neurodegenerative disorder after Alzheimer disease; its cause is unknown.

- Parkinson disease remains a clinical diagnosis, based on motor symptoms and signs; nonmotor symptoms, such as constipation, anosmia, rapid eye movement sleep behaviour disorder and depression, may precede motor symptoms by years.

- Factors such as symptom severity, degree of functional impairment and patient preference should be taken into account when choosing treatment. Levodopa remains the gold-standard therapy for treatment of motor symptoms of Parkinson disease.

- Motor fluctuations and dyskinesia will develop in most patients five to ten years into the disease while taking levodopa; many adjunctive oral therapies are available to reduce motor fluctuations.

- Surgical therapies, including deep brain stimulation and levodopacarbidopa intestinal gel, may be offered to patients who continue to have troublesome motor fluctuations and dyskinesia. 
been related to pathologies outside the brain, including the spinal cord and peripheral autonomic nervous system. ${ }^{14}$

\section{Who gets Parkinson disease?}

The exact cause of Parkinson disease is unknown, but it is assumed to be the result of a combination of environmental influences superimposed on genetic predisposition or susceptibility (Table 2). ${ }^{14-16}$ There is increasing evidence that the genetic and environmental insults leading to Parkinson disease commonly lead to abnormal forms of a normal protein, $\alpha$-synuclein, which seems to contribute to cell death. ${ }^{16,23}$ The onset of Parkinson disease can be categorized as juvenile (age $<21 \mathrm{yr}$ ), early onset (21-50 yr) and late onset (generally $>60 \mathrm{yr}$ ). ${ }^{24,25}$ The juvenile form is rare, is often familial (in as many as $50 \%$ of cases), is most frequently associated with a parkin gene mutation and has an atypical presentation. ${ }^{25,26}$ Of patients with Parkinson disease, 10\%-16\% have an affected first- or second-degree relative; first-degree relatives may have double the risk of Parkinson disease compared with the general population. ${ }^{26-29}$ In early- and late-onset Parkinson disease, the frequency of a positive family history is not statistically different. ${ }^{24}$

\section{How is the diagnosis made?}

Currently, diagnosis of Parkinson disease is based on clinical features from history and examination, and over time based on the response to dopamine agents and the development of motor fluctuations. ${ }^{30}$ Motor manifestations of the disorder (Table 3 ) begin asymmetrically, and commonly include a resting tremor, a soft voice (hypophonia), masked facies (initially presenting as reduced blink rate), small handwriting (micrographia), stiffness (rigidity), slowness of movements (bradykinesia), shuffling steps and difficulties with balance. A classic symptom is resting tremor, usually affecting one upper limb, although $20 \%$ of patients do not have it; $; 130 \%$ may first present with tremor in a lower extremity, and there may also be a lip, jaw or even tongue tremor at rest. ${ }^{31,46} \mathrm{Head}$ and voice tremors are uncommon, and one should consider essential tremor in the differential diagnosis in such cases. ${ }^{31}$ Of all the major features, bradykinesia has the strongest correlation with the extent of dopamine deficiency. ${ }^{47}$ Diagnosis has been formalized by the criteria of the UK Parkinson's Disease Society Brain Bank, ${ }^{31}$ with diagnostic accuracy of up to $90 \%$ (Box 2). ${ }^{48}$

Parkinson disease also has a multitude of nonmotor symptoms; some may precede the diagnosis, and others may present early or late (Table 3) after the diagnosis, based on motor features, is made. The frequencies of early nonmotor symptoms that may precede the diagnosis of Parkinson disease, including constipation, disorders of rapid eye movement sleep behaviour, depression and olfactory impairment, are listed in Table 3. Red flags suggesting an alter-

\begin{tabular}{|lll|}
\hline \multicolumn{2}{|l|}{ Table 1: Braak staging of Lewy body deposition ${ }^{10}$} & \multicolumn{1}{c|}{ Major symptoms } \\
\hline Stage & \multicolumn{1}{|c|}{ Sites affected by Lewy bodies } \\
\hline I & $\begin{array}{l}\text { Dorsal motor nucleus of the vagus nerve and } \\
\text { olfactory tract }\end{array}$ & Constipation, anosmia \\
\hline II & Locus coeruleus and subcoeruleus complex & Sleep and mood dysfunction \\
\hline III & Substantia nigra & Motor symptoms of Parkinson disease \\
\hline IV-VI & Cortical involvement & Dementia, psychosis \\
\hline
\end{tabular}

Table 2: Risk factors for Parkinson disease

\begin{tabular}{|c|c|c|}
\hline \multirow[b]{2}{*}{ Nonmodifiable risk factors ${ }^{14-16}$} & \multicolumn{2}{|c|}{ Modifiable risk factors } \\
\hline & Increased risk & Possible decreased risk \\
\hline $\begin{array}{l}\text { - Age (mean age } 65 \mathrm{yr}) \\
\text { - Sex (M:F = } 1.5: 1.0) \\
\text { - Genetics ( } 10 \% \text { of cases) } \\
\text { - LRRK2 mutation (most common) } \\
\text { - Glucocerebrosidase gene mutation } \\
\text { - Parkin mutation (juvenile onset) }\end{array}$ & $\begin{array}{l}\text { - Industrial exposure }{ }^{17} \\
\text { - Heavy metals (i.e., manganese, lead, } \\
\text { copper) } \\
\text { - Pesticides (i.e., rotenone, paraquat) } \\
\text { - Obstructive sleep apnea (maybe in } \\
\text { women) }{ }^{12}\end{array}$ & $\begin{array}{l}\text { - Smoking (may be protective) }{ }^{18} \\
\text { - Caffeine (may lower risk, relative risk } \\
\text { 0.69; does not imply causality) }{ }^{20}\end{array}$ \\
\hline
\end{tabular}


native diagnosis to idiopathic Parkinson disease, such as another parkinsonian syndrome, are listed in Appendix 1.

\section{How do early- and late-onset disease differ in presentation?}

Patients with early-onset Parkinson disease are less likely to have gait disturbance as the presenting symptom, but have more pronounced rigidity and bradykinesia than those with lateonset disease. ${ }^{49,50}$ In one study, presentation with resting tremor occurred in $41 \%$ of patients with early-onset disease and $63 \%$ of those with late-onset disease, ${ }^{49}$ but further studies have not shown a consistent difference for tremor onset between early- and late-onset Parkinson disease. ${ }^{24}$ Patients with early-onset disease have a slower disease progression, delayed onset of falls and longer survival. ${ }^{24}$ Treatment differences in early and late onset are outlined below.

\section{What tests or investigations are available to help with diagnosis?}

Parkinson disease is a clinical diagnosis, and magnetic resonance imaging (MRI) may be used only to exclude other causes, as listed in Appendix 1. Advancements in neuroimaging studies, including transcranial Doppler ultrasonography, ${ }^{51}$ positron emission tomography (PET), single-photon emission computed tomography (SPECT), morphometric MRI studies, tractography, functional MRI and perfusion imaging are being used to differentiate idiopathic Parkinson disease from other parkinsonian disorders. ${ }^{52,53}$

Radionuclide imaging modalities like PET and SPECT, using a dopamine transporter ligand, have become the best approach to assess dopamine metabolism and deficiency. Tracer uptake is reduced maximally in the posterior or dorsal striatum and is asymmetric in Parkinson disease. ${ }^{52,53}$

A subgroup of patients suspected of having new-onset Parkinson disease will have no evidence of dopaminergic deficit on dopamine transporter SPECT and fluorine-18 fluoro-Ldopa PET imaging scans. ${ }^{54}$ In this group of patients, progression of disease, by imaging or clinical measures, is minimal, as is their likelihood of developing idiopathic Parkinson disease. ${ }^{54}$ However, a few may eventually be diagnosed with Parkinson disease, based on clinical progression, imaging and genetic evidence and a positive response to levodopa. ${ }^{55}$

There are currently no biomarkers of proven clinical utility. Cerebrospinal fluid levels of $\alpha$-synuclein may predict cognitive decline but do not correlate with motor progression. ${ }^{56}$

\section{How is Parkinson disease treated?}

Dopaminergic medications are the mainstay of symptomatic therapy for motor symptoms in Parkinson disease. The mechanisms of action, starting and target doses and adverse effects of medications are summarized in Appendix 2, available

Table 3: Early and late motor and nonmotor features in patients with Parkinson disease

\begin{tabular}{|c|c|c|c|}
\hline Early motor features ${ }^{30,31}$ & $\begin{array}{l}\text { Early nonmotor features } \\
\text { (may precede the diagnosis) }\end{array}$ & $\begin{array}{l}\text { Late features } \\
\text { (usually develop } 5-10 \text { yr after } \\
\text { disease onset) }\end{array}$ & Late nonmotor features ${ }^{31-34}$ \\
\hline \multicolumn{4}{|c|}{$\begin{array}{l}\text { Note: } \mathrm{HR}=\text { hazard ratio, } \mathrm{REM}=\text { rapid eye movement. } \\
{ }^{*} \text { The risk of synucleinopathy (i.e., Parkinson disease, multiple system atrophy, Lewy body dementia) in patients with REM sleep behaviour disorder was reported } \\
\text { to be } 30 \% \text { at } 3 \text { years, rising to } 66 \% \text { at } 7.5 \text { years.45 Advanced age (HR 1.07), olfactory loss (HR 2.8), abnormal colour vision (HR 3.1), subtle motor dysfunction } \\
\text { (HR 3.9) and nonuse of antidepressants (HR 3.5) identified higher risk of disease conversion. }{ }^{45}\end{array}$} \\
\hline
\end{tabular}


at www.cmaj.ca/lookup/suppl/doi:10.1503/ cmaj.151179/-/DC1. Discovered in the 1960s, levodopa was the first symptomatic treatment for Parkinson disease, followed by the availability of dopamine agonists and monoamine oxidase B inhibitors. Until recently, the decision regarding which treatment to initiate has been debated. There is no one medication that is recommended for treatment initiation currently, but factors such as symptom severity, embarrassment, ability to perform activities, cost and patient preference should be taken into account. If symptoms are very mild, the patient may choose not to begin therapy. ${ }^{34,57}$

Because patients with early-onset disease are more likely to develop levodopa-induced abnormal movements (dyskinesia), dopamine agonists are often introduced as initial treatment; however, this early advantage of dopamine agonists over levodopa diminishes over time (about $10 \mathrm{yr}$ ). ${ }^{34}$ There is also some controversial evidence for neuroprotection with the monoamine oxidase $\mathrm{B}$ inhibitor rasagiline at the $1 \mathrm{mg}$ daily dose, ${ }^{58}$ however, its cost is not covered in most provinces and may require application to the exceptional access program, as is done in Ontario.

Because of the increased risk of neuropsychiatric adverse effects from dopamine agonists in late-onset Parkinson disease, levodopa is often started first. ${ }^{34}$ Levodopa achieves somewhat better control of motor symptoms of Parkinson disease than dopamine agonists and monoamine oxidase B inhibitors, but dyskinesias and motor fluctuations develop after long-term use or highdose treatment. ${ }^{59}$ The patient will likely need multiple medication adjustments over time with the addition of adjunctive treatments. ${ }^{60,61}$ Most

\section{Box 2: Criteria of the UK Parkinson's Disease Society Brain Bank for} diagnosing Parkinson disease ${ }^{31}$

- Bradykinesia and at least one of the following:

- Rigidity

- Resting tremor (4-6 Hz)

- Postural instability not caused by primary visual, vestibular, cerebellar or proprioceptive dysfunction

- Exclusion of other causes of parkinsonism (Appendix 1, available at www. cmaj.ca/lookup/suppl/doi:10.1503/cmaj.151179/-/DC1)

- At least three of the following supportive (prospective) features:

- Unilateral onset

- Persistent asymmetry primarily affecting the side of onset

- Resting tremor (hand, leg or jaw; low frequency [4-5 Hz], asymmetric, disappears with action)

- Excellent response to levodopa (70\%-100\%)

- Progressive disorder

- Severe levodopa-induced chorea (dyskinesias)

- Levodopa response for five years or more

Clinical course of 10 years or more patients taking dopamine agonists will also need levodopa after two to five years. ${ }^{62}$ Nonmotor symptoms and their management are reviewed in Appendix 3, available at www.cmaj.ca/ lookup/supp1/doi:10.1503/cmaj.151179/-/DC1.

Because Parkinson-plus syndromes (e.g., multiple system atrophy and progressive supranuclear palsy), respond in the very early stages to levodopa, this medication should be tried for at least several months with doses up to $1000 \mathrm{mg} / \mathrm{d}$ before concluding nonresponsiveness. ${ }^{63}$ The diagnosis should also be re-evaluated after a trial of levodopa. Responsiveness to levodopa occurs in about $80 \%$ of patients with idiopathic Parkinson disease. ${ }^{63}$ Although bradykinesia and rigidity respond well to levodopa, this consistent response is not seen for tremor. ${ }^{64}$

Anticholinergics, such as trihexyphenidyl, may be used in patients with early-onset Parkinson disease and severe tremor, but not as a first choice owing to limited efficacy and propensity for neuropsychiatric adverse effects. ${ }^{57}$ Recent data show that injections of botulinum toxin may effectively treat tremor from Parkinson disease. ${ }^{65}$

Behavioural addictions and impulse control disorders occur in $5 \%$ of patients with Parkinson disease and up to $20 \%$ of those taking dopamine agonists. ${ }^{66,67}$ Risk factors for impulse control disorders include younger age (perhaps related to prescribing behaviour of dopamine agonists in this group), novelty-seeking personality, family history of addiction, use of dopamine agonists and prior history of impulse control disorders. ${ }^{66}$

Dopamine dysregulation syndrome is a form of addictive behaviour that occurs in up to $4 \%$ of patients and is characterized by compulsive overuse of dopaminergic medications, which are typically short-acting (e.g., levodopa and apomorphine), impairing physical, social and occupational functioning. ${ }^{67}$ Punding involves repetitive, often purposeless, stereotyped behaviours, such as sorting or disassembling, and occurs in up to $15 \%$ of patients with Parkinson disease. ${ }^{68}$ Impulse control disorders can occur anytime after starting dopamine agonists; dopamine dysregulation syndrome and punding can occur with use of short-acting dopaminergic agents, including levodopa. ${ }^{34}$

Antiparkinsonian medications should not be withdrawn abruptly to avoid acute akinesia or neuroleptic malignant syndrome. Dopamine agonists should not be rapidly discontinued because of the risk of dopamine agonist withdrawal syndrome (occurs in $15 \%$ of patients taking dopamine agonists; the risk is higher among those with impulse control disorders). ${ }^{69-71}$

About $40 \%$ of patients with Parkinson disease use one or more forms of alternative therapies to complement their standard treatments. ${ }^{72}$ Exercise 
therapy may be considered as a means of improving motor function in patients with Parkinson disease, but there is no good evidence that it is neuroprotective. ${ }^{73-75}$ There is good evidence for physiotherapy, but the effect often dissipates when the intervention stops. ${ }^{75,76}$ Physiotherapy should address specific motor features such as falls, freezing and deconditioning. For patients with early disease, it is reasonable to encourage exercise (e.g., gym settings, regular walks or even dance therapy). ${ }^{75,77}$ Speech therapy may be considered to improve speech volume, with evidence in favour of the Lee Silverman Voice Treatment. ${ }^{78}$ Occupational therapy should be employed for practical home issues and activities of daily living, ${ }^{75}$ and may be helpful with driving assessments.

\section{Drugs that should be avoided}

Drugs that block dopamine receptors can result in parkinsonism or substantially worsen motor symptoms in patients with Parkinson disease and may lead to neuroleptic malignant syndrome. These include neuroleptics, such as haloperidol, thioridazine, chlorpromazine, promethazine, fluphenazine, risperidone and olanzapine; antiemetics, such as prochlorperazine and metoclopramide; tetrabenazine; and antihypertensives, such as methyldopa. ${ }^{79,80}$ Meperidine should be avoided in those receiving monoamine oxidase $\mathrm{B}$ inhibitors. ${ }^{81}$

\section{Managing motor and nonmotor symptoms in advanced disease}

Most patients respond well to levodopa; however, in $40 \%-50 \%$ of patients, motor fluctuations and dyskinesias will develop within five years of chronic levodopa treatment and in 70\%-80\%, after 10 years of treatment. ${ }^{34,82,83}$ Motor fluctuations are unexpected variations in the motor response, which may be erratic, to dopaminergic therapy, whereas dyskinesias are unwanted and intrusive, predominantly choreiform, movements resulting from levodopa (Appendices 4 and 5, available at www.cmaj.ca/lookup/suppl/doi :10.1503/cmaj.151179/-/DC1). ${ }^{84}$ Dyskinesias are less likely to develop in patients receiving less than 400-500 mg per day of levodopa. ${ }^{85}$ A higher cumulative incidence of dyskinesias, wearing off and on-off fluctuations in symptoms occurs in patients with early-onset disease and perhaps in women (Appendices 4 and 5). ${ }^{24,61,82,86,87}$ Dyskinesias may indicate better response to medication, and most patients prefer to be "on" with dyskinesia than "off." 87

In one study, $20 \%$ of patients with Parkinson disease had troublesome motor fluctuations and $4 \%$ had dyskinesias by five years, which were severe enough to require treatment change ${ }^{88}$ Catechol $O$-methyltransferase (COMT) inhibitors, such as entacapone, given with each tablet of levodopa-carbidopa; monoamine oxidase B inhibitors, such as rasagiline or selegiline; and dopamine agonists, such as pramipexole, ropinirole, rotigotine patch and bromocriptine, may be offered to reduce "off" time. ${ }^{57}$ Ergot derivatives, such as bromocriptine, should be used with caution due to risks of pulmonary and cardiac valve fibrosis. Modified-release levodopa preparations, such as controlled-release preparations, may be used to reduce motor fluctuations, but should not be used as a first choice. There is evidence that use of combination forms of levodopa-carbidopa with COMT inhibitors is associated with earlier onset and increased frequency of dyskinesias. ${ }^{89}$ Amantadine, an antiviral with antiglutamatergic effects, may be considered to reduce dyskinesias; it is effective in $60 \%-70 \%$ of patients (level C evidence, as defined in Appendix 2)..$^{90}$ Axial symptoms, including postural instability and gait, tend to occur later in the disease and may be less responsive to dopaminergic therapies. There is evidence for trying cholinesterase inhibitors and/ or methylphenidate (level U [Appendix 2]). ${ }^{91}$

In advanced Parkinson disease, many disabling nonmotor symptoms emerge that are not improved by levodopa. ${ }^{42}$ Nonmotor symptoms and their management are reviewed in Appendix 3.

\section{Available of disease-modifying therapies}

No treatment has yet been found to be conclusively neuroprotective. Trials that have failed to show any convincing evidence of disease modification or slowed progression of Parkinson disease are listed in Appendix 6, available at www.cmaj. ca/lookup/suppl/doi:10.1503/cmaj.151179/-/DC1.

\section{What has changed in the treatment of advanced Parkinson disease?}

In advanced Parkinson disease, the efficacy of levodopa can decline and fluctuate throughout the day switching between "on" and "off" medication periods..$^{92}$ The motor and nonmotor fluctuations mirror those seen in levodopa plasma concentrations resulting from levodopa's short half-life. ${ }^{93}$ Providing continuous dopaminergic stimulation is the goal of treating fluctuations in patients with advanced Parkinson disease. ${ }^{94-96}$ We now have surgical options, including deep brain stimulation and levodopacarbidopa intestinal gel, to provide treatment to such patients. Currently, deep brain stimulation has the highest level of evidence with the largest 
number of randomized controlled trials. ${ }^{97}$ Emerging therapies currently being studied in Parkinson disease are listed in Appendix 7, available at www.cmaj.ca/lookup/suppl/doi :10.1503/cmaj.151179/-/DC1.

\section{Deep brain stimulation}

Deep brain stimulation was approved in 2002 as an adjunctive therapy in reducing motor fluctuation in advanced Parkinson disease (level C [Appendix 2]). ${ }^{57}$ The globus pallidus interna and the subthalamic nucleus are accepted targets for this procedure, with similar improvements in motor function and similar adverse events. ${ }^{98,99}$ Patients with subthalamic nucleus stimulation required lower doses of dopaminergic medications, but depression worsened after subthalamic nucleus stimulation and improved

Box 3: Candidacy for deep brain stimulation ${ }^{100}$
Good candidates
- Adequate response to dopaminergic therapy
- Presence of on-off fluctuations
- Age $<70$ yr ${ }^{84}$
- Medication-resistant tremor
- Reasonable cognitive function
Borderline candidates*
- Severe dyskinesia with a poor on-off dopaminergic response
- On-off fluctuations with moderate cognitive function
- On-off fluctuations with a poor on-off dopaminergic response
- Medication-resistant tremor with moderate cognitive dysfunction
- Medication-resistant tremor with a poor on-off dopaminergic response
Poor candidates
- Severe dementia
- Severe autonomic dysfunction
- Poor dopaminergic response
- Atypical parkinsonism (e.g., corticobasal degeneration, progressive
- - Unstable psychiatric disease
- Absence of a dedicated caregiver
multidisciplinary team.

Table 4: Prognostic factors in Parkinson disease ${ }^{57}$

Predictors of a more benign course Predictors of a more rapid course

\begin{tabular}{|c|c|}
\hline $\begin{array}{l}\text { - Early onset }{ }^{24} \\
\text { - Tremor-predominant } \\
\text { - Female sex }{ }^{118}\end{array}$ & $\begin{array}{l}\text { - Late onset }{ }^{24} \\
\text { - Male sex }{ }^{118} \\
\text { - Postural instability (predominant gait } \\
\text { difficulty) } \\
\text { - Rigidity or bradykinesia as first symptom } \\
\text { - Dementia } \\
\text { - Poor response to levodopa } \\
\text { - Associated comorbidities (e.g., stroke) }\end{array}$ \\
\hline
\end{tabular}

after globus pallidus interna stimulation. Most centres select patients for deep brain stimulation on the basis of the nature of the patient's symptoms and the likelihood of a response to the therapy (Box 3).

The response to deep brain stimulation is equal to the best response on levodopa, but more effective than medical therapy in improving "on" time without troublesome dyskinesias. ${ }^{101,102}$ Deep brain stimulation typically improves levodoparesponsive symptoms (e.g., tremor, bradykinesia, rigidity) and on-off fluctuations and dyskinesias, whereas impairments in gait, balance and speech are less likely to improve. Patients should be considered for deep brain stimulation only if adequate trials of multiple medications for Parkinson disease (e.g., levodopa-carbidopa, dopamine agonists, monoamine oxidase $\mathrm{B}$ inhibitors and amantadine) have been unsuccessful. ${ }^{100}$ Although duration of efficacy is not clearly established, patients who undergo deep brain stimulation may have sustained benefit for at least 10 years. ${ }^{100} \mathrm{~A}$ recent study suggests that deep brain stimulation for Parkinson disease may be offered earlier for patients (mean age $52 \mathrm{yr}$, disease duration $7.5 \mathrm{yr}$ ) just beginning to have motor fluctuations. ${ }^{103}$ Thalamic deep brain stimulation may be considered as an option in patients who predominantly have disabling tremor where subthalamic nucleus stimulation cannot be performed. ${ }^{57}$

Adverse events are typically related to lead placement during surgery for deep brain stimulation, and the most worrisome include infection, requiring device removal and antibiotics $(1.2 \%-15.2 \%)$, and intracranial hemorrhage $(5 \%)$, causing permanent deficit or death in $1.1 \%$ of patients. ${ }^{100}$ Diathermy, electrocautery and MRI should be avoided in patients with deep brain stimulation. ${ }^{104}$

Surgery for deep brain stimulation can cost between US\$35 000-\$50 000 and \$70 000$\$ 100000$ for bilateral procedures. ${ }^{105}$ The cost for this procedure is covered in Canada.

\section{Levodopa-carbidopa intestinal gel}

For patients who are not candidates for or decline deep brain stimulation, levodopacarbidopa intestinal gel may be considered. This gel is pumped into the jejunum, via percutaneous tube insertion, recently approved for the treatment of motor fluctuations in Parkinson disease. ${ }^{106,107}$ The dose of required levodopa-carbidopa intestinal gel is equivalent to the daily oral levodopa dose, but delivered continuously during the waking day (i.e., 16 hours), without concerns of reduced absorption. Unlike deep brain stimulation, there is no age limitation or neurocognitive exclusion to levodopa-carbidopa intes- 
tinal gel. ${ }^{84}$ However, patients with severe dementia who may be unable to retain a jejunal tube are generally excluded.

Administration of levodopa-carbidopa intestinal gel has been shown to result in faster absorption, comparable bioavailability and reduced intrasubject variability in levodopa concentrations compared with oral levodopa-carbidopa. ${ }^{108}$ Studies of levodopa-carbidopa intestinal gel in advanced Parkinson disease have shown a significant reduction in motor fluctuations and dyskinesias, but do not eliminate them completely. ${ }^{84,109,110}$ In a seven-year follow-up study involving 59 patients with advanced Parkinson disease treated with levodopa-carbidopa intestinal gel, $90 \%$ of patients reported improvement in quality of life, autonomy and clinical global status. ${ }^{111}$

Discontinuation has been reported in 19\%$25 \%$ of patients receiving levodopa-carbidopa intestinal gel who were followed for two to seven years; discontinuation was owing to adverse drug reactions, procedure- and device-related events, poor compliance and/or lack of efficacy. ${ }^{111,112}$

The cost of the gel is about Can $\$ 166$ per day or roughly $\$ 60000$ per year, ${ }^{113}$ and may require provincial approval applications for coverage.

\section{What is the prognosis?}

Life expectancy is decreased in Parkinson disease (odds ratio 2.56, i.e., the mortality risk is 2.56 times higher than similar age-matched people without Parkinson disease), and medical treatments do not appear to alter mortality or delay the onset of nonmotor symptoms. ${ }^{114}$ Although progression is slower in patients with early-onset disease and there is longer absolute survival, this comes at the expense of increased years of life lost (11 yr lost in early-onset disease v. 4 yr in late-onset disease). ${ }^{24,115}$ Late-onset Parkinson disease is associated with more rapid disease progression and cognitive decline, ${ }^{116}$ which may be related to a lack of compensatory strategies against cell death. ${ }^{24}$ Data on the long-term outcomes and in the older population are lacking. ${ }^{117}$

Prognostic factors are summarized in Table 4. Patients with early-onset disease were slower to reach stage III-V on the Hoehn and Yahr scale ${ }^{119}$ (Appendix 8a, available at www.cmaj.ca/lookup/ suppl/doi:10.1503/cmaj.151179/-/DC1). The distribution of Hoehn and Yahr staging according to disease duration is listed in Appendix 8b. In the Rotterdam Study, Parkinson disease was associated with an increased risk of dementia (hazard ratio [HR] 2.8) and increased risk of death (HR 1.8). When dementia prevalence was controlled for, risk of mortality was only slightly higher than among the general population. ${ }^{120}$

\section{Conclusion}

Parkinson disease is a neurodegenerative disorder that is clinically diagnosed based on its motor features, with nonmotor symptoms being recognized commonly. The etiology remains unknown, but includes a combination of genetic and environmental risk factors, most commonly age and sex. Factors associated with increased mortality may include severity of parkinsonism, rate of worsening of parkinsonism, poor response to levodopa, early gait dysfunction and symmetry of parkinsonism. Some of these features may account for the possibility of a misdiagnosis of a Parkinson-plus syndrome as idiopathic Parkinson disease, and it is important to recognize this challenge in the differential diagnosis.

Although no neuroprotective treatments are yet available, many medical and surgical therapies exist that may be used in different stages throughout the course of disease for symptomatic treatment of both motor and nonmotor features. With the variety of ongoing trials on emerging therapies, we may see better options in the near future.

\section{References}

1. Dorsey ER, Constantinescu R, Thompson JP, et al. Projected number of people with Parkinson disease in the most populous nations, 2005 through 2030. Neurology 2007;68:384-6.

2. de Rijk MC, Tzourio C, Breteler MM, et al. Prevalence of parkinsonism and Parkinson's disease in Europe: the EUROPARKINSON Collaborative Study. European Community Concerted Action on the Epidemiology of Parkinson's disease. J Neurol Neurosurg Psychiatry 1997;62:10-5.

3. Twelves D, Perkins KSM, Counsell C. Systematic review of incidence studies of Parkinson's disease. Mov Disord 2003;18:19-31.

4. de Lau LML, Breteler MMB. Epidemiology of Parkinson's disease. Lancet Neurol 2006;5:525-35.

5. de Lau LML, Giesbergen PCLM, de Rijk MC, et al. Incidence of parkinsonism and Parkinson disease in a general population: the Rotterdam Study. Neurology 2004;63:1240-4.

6. Dahodwala N, Siderowf A, Xie M, et al. Racial differences in the diagnosis of Parkinson's disease. Mov Disord 2009;24: 1200-5.

7. Scope (prevalence and incidence) of neurological conditions. In: Mapping connections: an understanding of neurological conditions in Canada. Ottawa: Public Health Agency of Canada; 2014. Available: www.phac-aspc.gc.ca/publicat/cd-mc/mc-ec/ section-3-eng.php (accessed 2015 Aug. 30).

8. Alexander GE, DeLong MR, Strick PL. Parallel organization of functionally segregated circuits linking basal ganglia and cortex. Annu Rev Neurosci 1986;9:357-81.

9. Lang AE, Lozano AM. Parkinson's disease. First of two parts. N Engl J Med 1998;339:1044-53.

10. Braak H, Del Tredici K, Rüb U, et al. Staging of brain pathology related to sporadic Parkinson's disease. Neurobiol Aging 2003; 24:197-211.

11. Jankovic J. Progression of Parkinson disease: Are we making progress in charting the course? Arch Neurol 2005;62:351-2.

12. Kim HJ, Jeon BS, Paek SH. Nonmotor symptoms and subthalamic deep brain stimulation in Parkinson's disease. J Mov Disord 2015;8:83-91

13. Hemmerle AM, Herman JP, Seroogy KB. Stress, depression and Parkinson's disease. Exp Neurol 2012;233:79-86.

14. Kieburtz K, Wunderle KB. Parkinson's disease: evidence for environmental risk factors. Mov Disord 2013;28:8-13.

15. Racette BA, Willis AW. Time to change the blind men and the elephant approach to Parkinson disease? Neurology 2015;85: 190-6.

16. Covy JP, Giasson BI. $\alpha$-Synuclein, leucine-rich repeat kinase-2, and manganese in the pathogenesis of Parkinson disease. Neurotoxicology 2011;32:622-9. 
17. Wright Willis A. Evanoff BA, Lian M, et al. Geographic and ethnic variation in Parkinson disease: a population-based study of us medicare beneficiaries. Neuroepidemiology 2010;34:143-51.

18. Ritz B, Lee P, Lassen CF. Arah OA. Parkinson disease and smoking revisited: ease of quitting is an early sign of the disease. Neurology 2014;83:1396-402.

19. Willis AW, Evanoff BA, Lian M, et al. Metal emissions and urban incident parkinson disease: a community health study of medicare beneficiaries by using geographic information systems. Am J Epidemiol 2010;172:1357-63.

20. Hernán MA, Takkouche B, Caamaño-Isorna F, et al. A metaanalysis of coffee drinking, cigarette smoking, and the risk of Parkinson's disease. Ann Neurol 2002;52:276-84

21. Ritz BR, Manthripragada AD, Costello S, et al. Dopamine transporter genetic variants and pesticides in Parkinson's disease. Environ Health Perspect 2009;117:964-9.

22. Sheu JJ, Lee HC, Lin HC, et al. A 5-year follow-up study on the relationship between obstructive sleep apnea and Parkinson disease. J Clin Sleep Med 2015;11:1403-8.

23. Luk KC, Lee VMY. Modeling Lewy pathology propagation in Parkinson's disease. Parkinsonism Relat Disord 2014;20(1 Suppl):S85-7

24. Ferguson LW, Rajput AH, Rajput A. Early-onset vs. late-onset Parkinson's disease: a clinical-pathological study. Can J Neurol Sci 2016;43:113-9.

25. Schrag A, Schott JM. Epidemiological, clinical, and genetic characteristics of early-onset parkinsonism. Lancet Neurol 2006;5:355-63

26. Schrag A, Ben-Shlomo Y, Brown R, et al. Young-onset Parkinson's disease revisited - clinical features, natural history, and mortality. Mov Disord 1998;13:885-94.

27. Payami H, Larsen K, Bernard S, et al. Increased risk of Parkinson's disease in parents and siblings of patients. Ann Neurol 1994;36:659-61.

28. Marder K, Tang MX, Mejia H, et al. Risk of Parkinson's disease among first-degree relatives: a community-based study. Neurology 1996;47:155-60.

29. Lazzarini AM, Myers RH, Zimmerman TR, et al. A clinical genetic study of Parkinson's disease: evidence for dominant transmission. Neurology 1994:44:499-506.

30. Suchowersky O, Reich S, Perlmutter J, et al. Practice parameter: diagnosis and prognosis of new onset Parkinson disease (an evidence-based review): report of the Quality Standards Subcommittee of the American Academy of Neurology. Neurology 2006;66:968-75.

31. Jankovic J. Parkinson's disease: clinical features and diagnosis. J Neurol Neurosurg Psychiatry 2008;79:368-76.

32. Lim SY, Lang AE. The nonmotor symptoms of Parkinson's disease: an overview. Mov Disord 2010;25(1 Suppl):S123-30.

33. Sakakibara R, Kishi M, Ogawa E, et al. Bladder, bowel, and sexual dysfunction in Parkinson's disease. Parkinsons Dis 2011;2011:924605

34. Connolly BS, Lang AE. Pharmacological treatment of Parkinson disease: a review. JAMA 2014;311:1670-83.

35. Rosenblum S, Samuel M, Zlotnik S, et al. Handwriting as an objective tool for Parkinson's disease diagnosis. J Neurol 2013;260:2357-61.

36. Rolinski M, Szewczyk-Krolikowski K, Tomlinson PR, et al. REM sleep behaviour disorder is associated with worse quality of life and other non-motor features in early Parkinson's disease. J Neurol Neurosurg Psychiatry 2014;85:560-6.

37. Schenck CH, Boeve BF, Mahowald MW. Delayed emergence of a parkinsonian disorder or dementia in $81 \%$ of older men initially diagnosed with idiopathic rapid eye movement sleep behavior disorder: a 16-year update on a previously reported series. Sleep Med 2013;14:744-8.

38. Lavault S, Leu-Semenescu S, Tezenas Du Montcel S, et al. Does clinical rapid eye movement behavior disorder predict worse outcomes in Parkinson's disease? J Neurol 2010;257:1154-9.

39. Aarsland D, Påhlhagen S, Ballard CG, et al. Depression in Parkinson disease - epidemiology, mechanisms and management. Nat Rev Neurol 2011;8:35-47.

40. Siderowf A, Jennings D, Eberly S, et al. Impaired olfaction and other prodromal features in the Parkinson At-Risk Syndrome Study. Mov Disord 2012;27:406-12.

41. Liu R, Umbach DM, Peddada SD, et al. Potential sex differences in nonmotor symptoms in early drug-naive Parkinson disease. Neurology 2015;84:2107-15.

42. Hely MA, Morris JGL, Reid WGJ, et al. Sydney Multicenter Study of Parkinson's disease: non-L-dopa-responsive problems dominate at 15 years. Mov Disord 2005;20:190-9.

43. Rocchi C, Pierantozzi M, Galati S, et al. Autonomic function tests and MIBG in Parkinson's disease: correlation to disease duration and motor symptoms. CNS Neurosci Ther 2015;21:727-32.
44. Mostile G, Jankovic J. Treatment of dysautonomia associated with Parkinson's disease. Parkinsonism Relat Disord 2009; 15(3 Suppl):S224-32.

45. Postuma RB, Gagnon J-F, Bertrand J-A, et al. Parkinson risk in idiopathic REM sleep behavior disorder: preparing for neuroprotective trials. Neurology 2015;84:1104-13.

46. Baumann CR. Epidemiology, diagnosis and differential diagnosis in Parkinson's disease tremor. Parkinsonism Relat Dis ord 2012;18:S90-2.

47. Vingerhoets FJG, Schulzer M, Calne DB, et al. Which clinical sign of Parkinson's disease best reflects nigrostiatal lesion? Ann Neurol 1997;41:58-64.

48. Hughes AJ, Daniel S, Lees A. Improved accuracy of clinical diagnosis of Lewy body. Neurology 2001;57:1497-9.

49. Gibb WR, Lees AJ. A comparison of clinical and pathological features of young- and old-onset Parkinson's disease. Neurology 1988;38:1402-6.

50. Gomez Arevalo G, Jorge R, Garcia S, et al. Clinical and pharmacological differences in early- versus late-onset Parkinson's disease. Mov Disord 1997;12:277-84.

51. Alonso-Cánovas A, Lopez-Sendon JL, Buisan J, et al. Sonography for diagnosis of Parkinson disease - from theory to practice: a study on 300 participants. J Ultrasound Med 2014; 33:2069-74.

52. Stoessl AJ, Martin WRW, McKeown MJ, et al. Advances in imaging in Parkinson's disease. Lancet Neurol 2011;10:987-1001.

53. Stoessl AJ, Lehericy S, Strafella AP. Imaging insights into basal ganglia function, Parkinson's disease, and dystonia. Lancet 2014;384:532-44.

54. Marek K, Seibyl J, Eberly S, et al. Longitudinal follow-up of SWEDD subjects in the PRECEPT Study. Neurology 2014; 82:1791-7.

55. Erro R, Schneider SA, Stamelou M, et al. What do patient with scans without evidence of dopaminergic deficit (SWEDD) have? New evidence and continuing controversies. J Neurol Neurosurg Psychiatry 2016;87:319-23.

56. Stewart T, Liu C, Ginghina C, et al. Cerebrospinal fluid $\alpha$-synuclein predicts cognitive decline in Parkinson disease progression in the DATATOP cohort. Am J Pathol 2014;184:966-75.

57. Grimes D, Gordon J, Snelgrove B, et al. Canadian guidelines on Parkinson's Disease. Can J Neurol Sci 2012;39(Suppl 4): S1-30.

58. Olanow CW, Rascol O, Hauser R, et al. A double-blind, delayed-start trial of rasagiline in Parkinson's disease. $N$ Engl J Med 2009;361:1268-78.

59. Gray R, Ives N, Rick C, et al.; PD Med Collaborative Group. Long-term effectiveness of dopamine agonists and monoamine oxidase B inhibitors compared with levodopa as initial treatment for Parkinson's disease (PD MED): a large, open-label, pragmatic randomised trial. Lancet 2014;384:1196-205.

60. Rascol O, Brooks D, Korczyn AD, et al. A five-year study of the incidence of dyskinesia in patients with early Parkinson's disease who were treated with ropinirole or levodopa. $N$ Engl J Med 2000;342:1484-91

61. The Parkinson Study Group. Pramipexole vs. levodopa as initial treatment for Parkinson disease: a randomized controlled trial. Parkinson Study Group. JAMA 2000;284:1931-8.

62. Holloway RG, Shoulson I, Fahn S, et al. Pramipexole vs levodopa as initial treatment for Parkinson disease: a 4-year randomized controlled trial [published erratum in Arch Neurol 2005;62:430] Arch Neurol 2004;61:1044-53.

63. Hughes AJ, Daniel SE, Blankson S, et al. A clinicopathologic study of 100 cases of Parkinson's disease. Arch Neurol 1993; 50:140-8.

64. Jiménez MC, Vingerhoets FJ. Tremor revisited: treatment of PD tremor. Parkinsonism Relat Disord 2012;18:S93-5.

65. Rahimi F, Samotus O, Lee J, et al. Effective management of upper limb parkinsonian tremor by incobotulinumtoxinA injections using sensor-based biomechanical patterns. Tremor Other Hyperkinet Mov (N Y) 2015;5:348.

66. Ceravolo R, Frosini D, Rossi C, et al. Impulse control disorders in Parkinson's disease: definition, epidemiology, risk factors, neurobiology and management. Parkinsonism Relat Disord 2009;15(4 Suppl):S111-5.

67. O'Sullivan SS, Evans AH, Lees AJ. Dopamine dysregulation syndrome: an overview of its epidemiology, mechanisms and management. CNS Drugs 2009;23:157-70.

68. Evans AH, Katzenschlager R, Paviour D, et al. Punding in Parkinson's disease: its relation to the dopamine dysregulation syndrome. Mov Disord 2004;19:397-405.

69. Solla P, Fasano A, Cannas A, et al. Dopamine agonist withdrawal syndrome (DAWS) symptoms in Parkinson's disease patients treated with levodopa-carbidopa intestinal gel infusion. Parkinsonism Relat Disord 2015;21:968-71. 
70. Nirenberg MJ. Dopamine agonist withdrawal syndrome: implications for patient care. Drugs Aging 2013;30:587-92.

71. Pondal M, Marras C, Miyasaki J, et al. Clinical features of dopamine agonist withdrawal syndrome in a movement disorders clinic. J Neurol Neurosurg Psychiatry 2013;84:130-5

72. Ghaffari BD, Kluger B. Mechanisms for alternative treatments in Parkinson's disease: acupuncture, tai chi, and other treatments. Curr Neurol Neurosci Rep 2014;14:451.

73. Canning CG, Sherrington C, Lord SR, et al. Exercise for falls prevention in Parkinson disease: a randomized controlled trial. Neurology 2015;84:304-12.

74. Suchowersky O, Gronseth G, Perlmutter J, et al. Practice parameter: neuroprotective strategies and alternative therapies for Parkinson disease (an evidence-based review): Report of the Quality Standards Subcommittee of the American Academy of Neurology. Neurology 2006;66:976-82.

75. Bloem BR, de Vries NM, Ebersbach G. Nonpharmacological treatments for patients with Parkinson's disease. Mov Disord 2015;30:1504-20.

76. Deane KH, Jones D, Playford ED, et al. Physiotherapy for patients with Parkinson's disease: a comparison of techniques. Cochrane Database Syst Rev 2001;(3):CD002817.

77. Volpe D, Signorini M, Marchetto A, et al. A comparison of Irish set dancing and exercises for people with Parkinson's disease: a phase II feasibility study. BMC Geriatr 2013;13:54.

78. Mahler LA, Ramig LO, Fox C. Evidence-based treatment of voice and speech disorders in Parkinson disease. Curr Opin Otolaryngol Head Neck Surg 2015;23:209-15.

79. Ortí-Pareja M, Jiménez-Jiménez FJ, Vázquez A, et al. Druginduced tardive syndromes. Parkinsonism Relat Disord 1999; 5:59-65.

80. Burkhard PR. Acute and subacute drug-induced movement disorders. Parkinsonism Relat Disord 2014;20(1 Suppl):S108-12.

81. Nicholson G, Pereira AC, Hall GM. Parkinson's disease and anaesthesia. Br J Anaesth 2002;89:904-16.

82. Schrag A, Quinn N. Dyskinesias and motor fluctuations in Parkinson's disease. A community-based study. Brain 2000;123 (Pt 11):2297-305

83. Chase TN, Mouradian MM, Engber TM. Motor response complications and the function of striatal efferent systems. Neurology 1993;43(6 Suppl):S23-7.

84. Ossig C, Reichmann H. Treatment of Parkinson's disease in the advanced stage. J Neural Transm 2013;120:523-9.

85. Reichmann H. Modern treatment in Parkinson's disease, a personal approach. J Neural Transm 2016;123:73-80.

86. Kostic V, Przedborski S, Flaster E, et al. Early development of levodopa-induced dyskinesias and response fluctuations in young-onset Parkinson's disease. Neurology 1991;41:202-5.

87. Marras C, Lang A, Krahn M, et al. Quality of life in early Parkinson's disease: impact of dyskinesias and motor fluctuations. Mov Disord 2004;19:22-8.

88. Scott NW, Macleod AD, Counsell CE. Motor complications in an incident Parkinson's disease cohort. Eur J Neurol 2016;23:304-12.

89. Stocchi F, Rascol O, Kieburtz K, et al. Initiating levodopa/carbidopa therapy with and without entacapone in early Parkinson disease: the STRIDE-PD study Ann Neurol 2010;68:18-27.

90. Sawada H, Oeda T, Kuno S, et al. Amantadine for dyskinesias in Parkinson's disease: a randomized controlled trial. PLoS One 2010;5:e15298.

91. Kim SD, Allen NE, Canning CG, et al. Postural Instability in patients with Parkinson's disease. CNS Drugs 2013;27:97-112.

92. Ramirez-Zamora A, Molho E. Treatment of motor fluctuations in Parkinson's disease: recent developments and future directions. Expert Rev Neurother 2014;14:93-103.

93. Nyholm D, Lennernäs H, Gomes-Trolin C, et al. Levodopa pharmacokinetics and motor performance during activities of daily living in patients with Parkinson's disease on individua drug combinations. Clin Neuropharmacol 2002;25:89-96.

94. Gershanik O, Jenner P. Moving from continuous dopaminergic stimulation to continuous drug delivery in the treatment of Parkinson's disease. Eur J Neurol 2012;19:1502-8.

95. Nyholm D, Nilsson Remahl AL, Dizdar N, et al. Duodenal levodopa infusion monotherapy vs oral polypharmacy in advanced Parkinson disease. Neurology 2005;64:216-23.

96. van Laar T. Levodopa-induced response fluctuations in patients with Parkinson's disease: strategies for management. CNS Drugs 2003; 17:475-89.

97. Giugni JC, Okun MS. Treatment of advanced Parkinson's disease. Curr Opin Neurol 2014;27:450-60.

98. Follett KA, Weaver FM, Stern M, et al. Pallidal versus subthalamic deep-brain stimulation for Parkinson's disease. $N$ Engl J Med 2010;362:2077-91.
99. Odekerken VJJ, van Laar T, Staal MJ, et al. Subthalamic nucleus versus globus pallidus bilateral deep brain stimulation for advanced Parkinson's disease (NSTAPS study): a randomised controlled trial. Lancet Neurol 2013;12:37-44.

100. Okun MS. Deep-brain stimulation for Parkinson's disease. N Engl J Med 2012;367:1529-38.

101. Weaver FM, Follett K, Stern M, et al. Bilateral deep brain stimulation vs best medical therapy for patients with advanced Parkinson disease. JAMA 2009;301: 63-73.

102. Williams A, Gill S, Varma T, et al. Deep brain stimulation plus best medical therapy versus best medical therapy alone for advanced Parkinson's disease (PD SURG trial): a randomised, open-label trial. Lancet Neurol 2010;9:581-91.

103. Schuepbach WMM, Rau J, Knudsen K, et al. Neurostimulation for Parkinson's disease with early motor complications. $N$ Engl J Med 2013;368:610-22.

104. Medtronic $®$ DBS ${ }^{\mathrm{TM}}$ Therapy. Implanted neurostimulators. Information for prescribers. Available: http://manuals.medtronic.com/ wcm/groups/mdtcom_sg/@emanuals/@era/@neuro/documents/ documents/contrib 229535.pdf (accessed 2016 May 14).

105. Okun MS, Zeilman PR. Parkinson's disease: guide to deep brain stimulation therapy. Miami: National Parkinson Foundation; 2014. Available: www.parkinson.org/sites/default/files/Guide _to_DBS_Stimulation_Therapy.pdf (accessed 2016 May 14).

106. Duodopa [product monograph]. St. Laurent (QC): AbbVie Corporation; 2015. Available: www.abbvie.ca/content/dam/abbviecorp/ ca/english/docs/DUODOPA PM EN.pdf (accessed 2015 Aug. 30).

107. Pickut BA, Van Der Linden C, Dethy S, et al. Intestinal levodopa infusion: the Belgian experience. Neurol Sci 2014;35:861-6.

108. Othman AA, Dutta S. Population pharmacokinetics of levodopa in subjects with advanced Parkinson's disease: levodopa-carbidopa intestinal gel infusion vs. oral tablets. $\mathrm{Br} \mathrm{J}$ Clin Pharmacol 2014;78:94-105.

109. Zibetti M, Merola A, Ricchi V, et al. Long-term duodenal levodopa infusion in Parkinson's disease: a 3-year motor and cognitive follow-up study. J Neurol 2013;260:105-14.

110. Olanow CW, Kieburtz K, Odin P, et al. Continuous intrajejunal infusion of levodopa-carbidopa intestinal gel for patients with advanced Parkinson's disease: a randomised, controlled, double-blind, double-dummy study. Lancet Neurol 2014;13:141-9.

111. Zibetti M, Merola A, Artusi CA, et al. Levodopa/carbidopa intestinal gel infusion in advanced Parkinson's disease: a 7-year experience. Eur J Neurol 2014;21:312-8.

112. Antonini A, Odin P, Opiano L, et al. Effect and safety of duodenal levodopa infusion in advanced Parkinson's disease: a retrospective multicenter outcome assessment in patient routine care. J Neural Transm 2013;120:1553-8.

113. Ontario Ministry of Health and Long-Term Care. Formulary: Exceptional Access Program (EAP). DIN 02292165. Available: www.health.gov.on.ca/en/pro/programs/drugs/odbf/odbf_except _access.aspx (accessed 2016 May 17)

114. Clarke CE. Has drug therapy changed the natural history of Parkinson's disease? J Neurol 2010;257(2 Suppl):S262-7.

115. Wickremaratchi MM, Ben-Shlomo Y, Morris HR. The effect of onset age on the clinical features of Parkinson's disease. Eur J Neurol 2009;16:450-6.

116. Reid WGJ, Hely MA, Morris JGL, et al. Dementia in Parkinson's disease: a 20-year neuropsychological study (Sydney Multicentre Study). J Neurol Neurosurg Psychiatry 2011;82:1033-7.

117. Logroscino G. A community study outlines how to prevent Parkinson's disease motor complications in the clinic. Eur J Neurol 2016;23:231-2

118. Haaxma CA, Bloem BR, Borm GF, et al. Gender differences in Parkinson's disease. J Neurol Neurosurg Psychiatry 2007;78: 819-24.

119. Sato K, Hatano T, Yamashiro K, et al. Prognosis of Parkinson's disease: time to stage III, IV, V, and to motor fluctuations. Mov Disord 2006;21:1384-95.

120. de Lau LML, Schipper CMA, Hofman A, et al. Prognosis of Parkinson disease: risk of dementia and mortality: the Rotterdam Study. Arch Neurol 2005;62:1265-9.

Contributors: All of the authors contributed substantially to the conception of the manuscript. Philippe Rizek drafted the manuscript, which Niraj Kumar and Mandar Jog revised critically for intellectual content. All of the authors gave final approval of the version to be published and agreed to act as guarantors of the work.

Affiliation: Department of Clinical Neurological Sciences, Western University, London, Ont. 